\title{
Correction to: Safety Communication Tools and Healthcare Professionals' Awareness of Specific Drug Safety Issues in Europe: A Survey Study
}

\author{
Sieta T. de Vries ${ }^{1}\left(\mathbb{D} \cdot\right.$ Maartje J. M. van der Sar $^{1,2} \cdot$ Anna Marie Coleman $^{3} \cdot$ Yvette Escudero $^{4}$. \\ Alfonso Rodríguez Pascual ${ }^{4} \cdot$ Miguel-Ángel Maciá Martínez $^{4} \cdot$ Amelia Cupelli $^{5} \cdot$ Ilaria Baldelli $^{5} \cdot$ Ivana Šipić $^{6}$. \\ Adriana Andrić ${ }^{6} \cdot$ Line Michan $^{7} \cdot$ Petra Denig ${ }^{1} \cdot$ Peter G. M. Mol ${ }^{1,2} \cdot$ on behalf of SCOPE work package 6
}

Published online: 30 June 2020

(c) Springer Nature Switzerland AG 2020

\section{Correction to: Drug Saf (2018) 41:713-724 \\ https://doi.org/10.1007/s40264-018-0643-5}

In the original publication of the article, the headings of columns 3 and 4 in the data table of Fig. 2 were switched. In this correction, the original Fig. 2 (Fig. 1) and the correct Fig. 2 (Fig. 2) are published.

The original article can be found online at https://doi.org/10.1007/ s40264-018-0643-5.

Peter G. M. Mol

p.g.m.mol@umcg.nl

1 Department of Clinical Pharmacy and Pharmacology,

University of Groningen, University Medical Center

Groningen, Groningen, The Netherlands

2 Dutch Medicines Evaluation Board, Utrecht, The Netherlands

3 Health Products Regulatory Authority (HPRA), Dublin, Ireland

4 Spanish Agency for Medicines and Medical Devices (AEMPS), Madrid, Spain

5 Italian Medicines Agency (AIFA), Rome, Italy

6 Agency for Medicinal Products and Medical Devices of Croatia (HALMED), Zagreb, Croatia

7 Danish Medicines Agency (DKMA), Copenhagen, Denmark 
Fig. 1 Original version of Fig. 2 as published on 02 March 2018

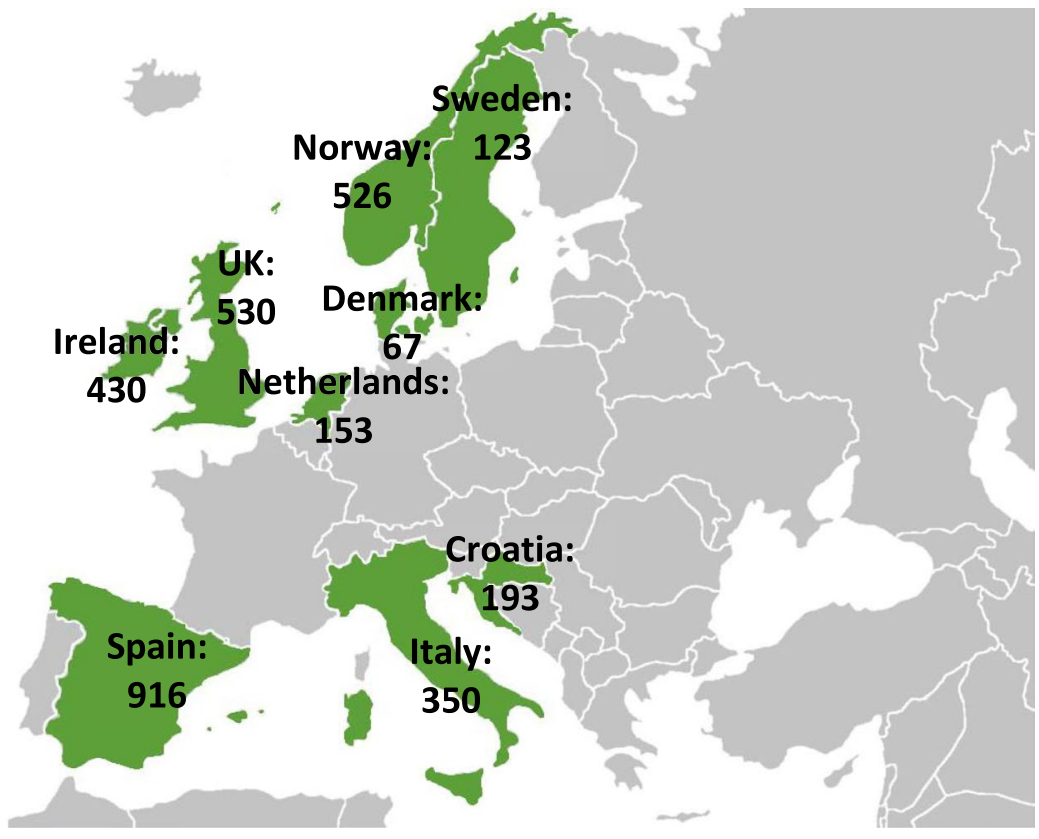

\begin{tabular}{llll}
\hline & General practitioners & Pharmacists & Cardiologists \\
\hline Croatia & 85 & 4 & 104 \\
Denmark & 25 & 7 & 35 \\
Ireland & 144 & 5 & 281 \\
Italy & 183 & 63 & 104 \\
Netherlands & 72 & 17 & 64 \\
Norway & 105 & 40 & 381 \\
Spain & 847 & 56 & 13 \\
Sweden & 108 & 15 & N/A \\
UK & 197 & 15 & 318 \\
\hline
\end{tabular}


Fig. 2 Corrected version of Fig. 2

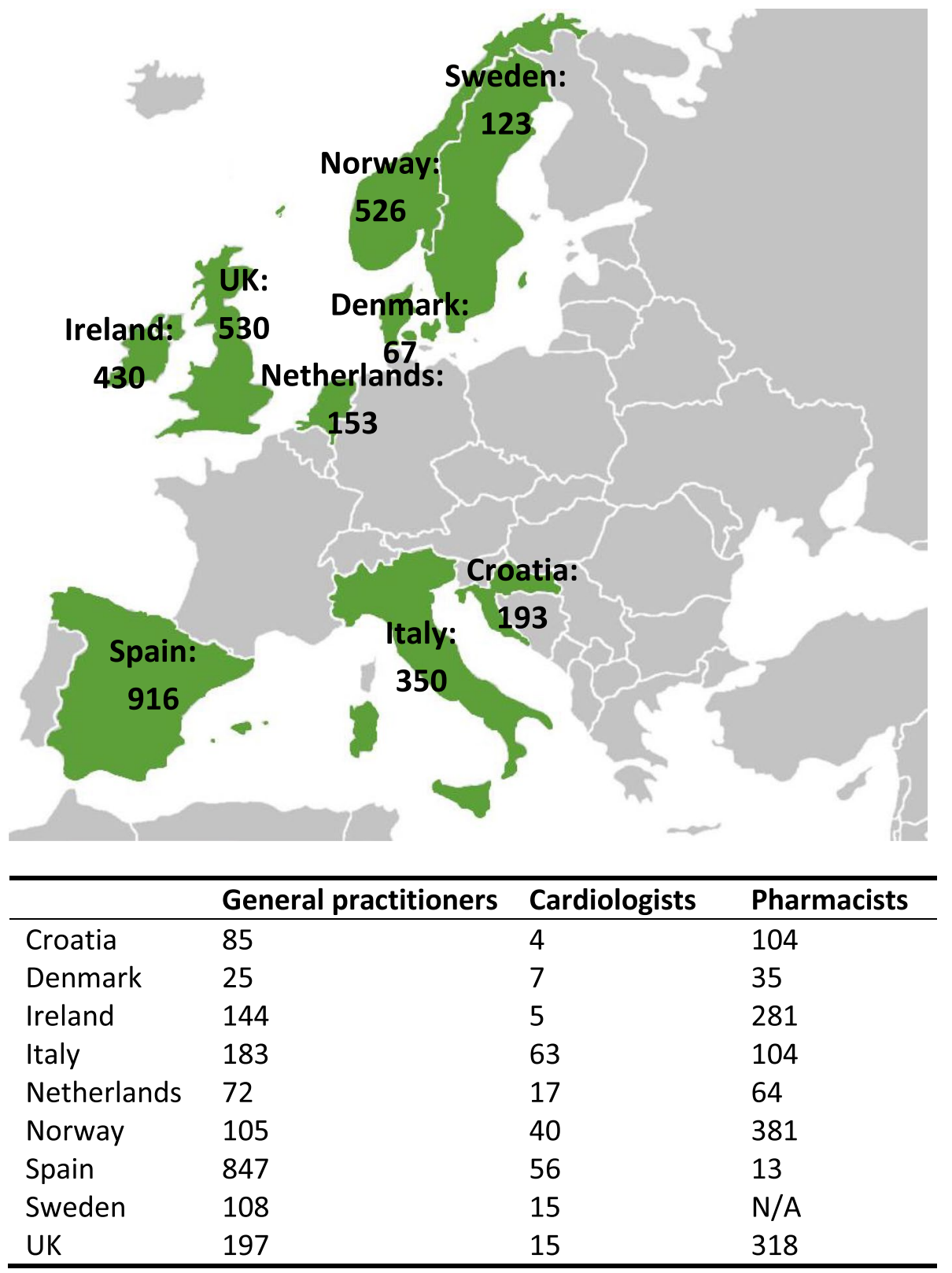

